\title{
Specimen size effect on the ductile-brittle transition reference temperature of A508-3 steel
}

\author{
Ziyang Zhou ${ }^{\mathrm{a}}$, Zhenfeng Tong ${ }^{\mathrm{a}, *}$, Guian Qian ${ }^{\mathrm{b}, *}$, Filippo Berto $^{\mathrm{c}}$ \\ ${ }^{a}$ China Institute of Atomic Energy, Beijing, China \\ ${ }^{\mathrm{b}}$ State Key Laboratory of Nonlinear Mechanics (LNM), Institute of Mechanics, Chinese Academy of Sciences, Beijing, China \\ ${ }^{\mathrm{c}}$ Department of Mechanical and Industrial Engineering, Norwegian University of Science and Technology (NTNU), Richard Birkelands vei $2 b, 7491$ Trondheim, Norway
}

\section{A R T I C L E I N F O}

\section{Keywords:}

Reactor pressure vessel steel

Fracture toughness

Ductile-brittle transition reference temperature

Size effect

J-Q theory

\begin{abstract}
A B S T R A C T
Fracture toughness is a key parameter for evaluating the structural integrity of reactor pressure vessels (RPV). In this paper, fracture toughness $K_{\mathrm{Jc}}$ of different sized RPV specimens is tested at different temperatures. Master Curve method was used to model $K_{\mathrm{Jc}}$ and the ductile-brittle transition reference temperature $\mathrm{T}_{0}$ is obtained. It is shown that the smaller the specimen size is, the lower the $\mathrm{T}_{0}$ value is. The small specimen is not able to completely replace the standard 1CT specimen in the irradiation surveillance program to obtain $\mathrm{T}_{0}$ and material toughness. J-Q theory is employed to study size effect and crack tip constraint effect on $K_{\text {Jc }}$. It is shown that Q (constraint) decreases as the specimen size decreases. A prediction model to transfer the reference temperature $T_{0}$ of different specimens is developed considering constraint effect by means of $\mathrm{Q}$.
\end{abstract}

\section{Introduction}

Reactor pressure vessel (RPV) is a key component in nuclear power plants that cannot be replaced. During the operation service, RPV materials subject to neutron embrittlement and hardening [1]. This leads to a change in the fracture behavior of the material, which in turn affects its service life and safety. Since the RPV material is ferritic steel, it is a bodycentered cubic structure, which itself has the characteristics of brittleness. This means that the Charpy-impact work of the material decreases significantly at low temperatures, and the transition from ductile to brittle fracture occurs. Correspondingly, the fracture microscopic mechanism of changes from dimple fracture to cleavage fracture in the ductile-brittle transition temperature range [2-4]. A small temperature variation will cause a large variation in fracture toughness $K_{\mathrm{Jc}}$. Even at the same temperature, the obtained $K_{\mathrm{Jc}}$ is very scattered, which makes the characterization of $K_{\mathrm{Jc}}$ quite difficult. With the development of the Master Curve method, $K_{\mathrm{Jc}}$ measured after irradiation can be directly used to construct a Weibull distribution, which is effective for the safety assessment of nuclear power plants [4-6]. This is now widely used in the service lifetime extension of nuclear power plants. Master Curve method will also be used in this paper to modeling $K_{\mathrm{Jc}}$ at different temperatures.

For the structural integrity of RPV, $K_{\mathrm{Jc}}$ should be tested for RPV irradiation surveillance program. Due to the large size of the standard compact tension specimen (1 CT) and the limited irradiation space in a RPV, smallsize specimens are generally used for the sake of efficiency. However, how to transfer $K_{\mathrm{Jc}}$ tested from small specimen to the standard specimen is questioning since there is crack tip constraint effect. For small-scale specimens, constraint loss may occur and extensive plastic deformation precedes unstable cleavage fracture. In such conditions, the evolving crack-tip plastic zones developing from the free surfaces affect strongly the levels of near-tip stress triaxiality (constraint) with increased loading [5]. Therefore, this paper employs the combination of experiment test and finite element analysis to study the influence of size (and crack tip constraint) effect on $K_{\mathrm{Jc}}$ and explores the link between different-sized specimens.

To date, there are a lot of methods to quantify constraint effect, e.g. small scale yielding correction (SSYC) [6,7], Q parameter [8,9] and the $T$ stress [10-13]. Both $Q$ parameter ( $Q$ stress, denoted as $Q$ in the paper) and $T$ stress give a quantitative value for the constraint effect. Neimitz and Dzioba [14] proposed an analytical formula to predict $K_{\text {Ic }}$ of high strength steels in the transition region, considering both in-plane and out-of-plane constraint effects. They combined $\mathrm{J}_{\mathrm{IC}}$ and Q for the constraint analysis. Gao et al. [15] used $\mathrm{T}$ stress to predict $\mathrm{T}_{0}$ variation between Single Edge Notch Bend specimens (SENB) with deep cracks and Compact Tension specimens (CT specimens) with deep and shallow cracks. Wallin [16] connected $\mathrm{T}_{0}$ to the specimen constraint, expressed in terms of the $\mathrm{T}$ stress. It is shown that there is nearly a linear relation between $\mathrm{T}_{0}$ and $\mathrm{T}$ stress

$T_{0} \approx T_{\text {deep }}+\frac{T_{\text {stress }}}{10 M P a / I^{\circ} \mathrm{C}}$ for $T$ stress $[\mathrm{MPa}]<0$

\footnotetext{
* Corresponding authors.

E-mail addresses: tony_tzf@163.com (Z. Tong), qianguian@imech.ac.cn (G. Qian).
} 


\author{
Nomenclature \\ $\mathrm{a}_{0} \quad$ initial crack length \\ A total area under the load-displacement curve \\ $A_{p} \quad$ area of the plastic section under the load-displacement \\ curve \\ $\mathrm{B}_{\mathrm{xT}} \quad$ actual specimen thickness $\mathrm{xT}=25.4 \times \mathrm{mm}$ \\ B no side groove specimen thickness \\ $\mathrm{B}_{0} \quad 1 \mathrm{~T}$ thickness, $25.4 \mathrm{~mm}$ \\ $B_{N} \quad$ net thickness of the open side groove specimen, for the \\ side grooved specimen $\mathrm{B}_{\mathrm{N}}=\mathrm{B}$ \\ C constant, taking different $\mathrm{K}_{\mathrm{Jc}}$ values for samples with dif- \\ ferent thicknesses \\ $\mathrm{C}_{0} \quad$ reciprocal of the slope of the elastic section of the load- \\ displacement curve \\ D variable \\ E Young's modulus \\ J J-integral \\ $\mathrm{J}_{\mathrm{e}} \quad$ elastic part of $\mathrm{J}$ integral \\ $\mathrm{J}_{\mathrm{p}} \quad$ plastic part of $\mathrm{J}$ integral \\ $\mathrm{K} \quad$ stress intensity factor \\ $\mathrm{K}_{\mathrm{e}} \quad$ the elastic component of the stress intensity factor \\ $\mathrm{K}_{\min } \quad$ threshold fracture toughness \\ $\mathrm{K}_{0} \quad$ scale parameter \\ $\mathrm{K}_{\mathrm{JC}} \quad$ equivalent fracture toughness obtained by the transfor- \\ mation of the critical $\mathrm{J}$ integral
}

$\mathrm{K}_{\mathrm{JC}(\mathrm{med})}$ median fracture toughness with a cumulative failure probability of $50 \%$

$\mathrm{M}_{\text {limit }}$ dimensionless deformation of the specimen specifying $\mathrm{M}_{\text {limit }}=30$

$\mathrm{P}_{\mathrm{s}} \quad$ load at cleavage fracture

$\mathrm{P}_{\mathrm{f}} \quad$ cumulative failure probability

Q Q-stress

$\mathrm{r} \quad$ distance from the crack tip

$\mathrm{T}_{0} \quad$ fracture toughness ductile-brittle transition reference temperature

$\mathrm{T}_{41 \mathrm{~J} / 28 \mathrm{~J}}$ temperature corresponding to the impact absorption work of $28 \mathrm{~J}$ or $41 \mathrm{~J}$

T-stress, $\mathrm{T}$ Second term of William's extension along $\mathrm{x}$ direction

$\mathrm{T}_{\text {Odeep }}$ reference temperature obtained from deeply cracked (high constraint) specimens

W specimen width

$\sigma_{\mathrm{y}} \quad$ yield stress at the test temperature

$\sigma_{\theta \theta} \quad$ stress field existing before the geometric crack tip

$\sigma_{(\theta \theta) \text { ref }}$ reference solution which is obtained from the standard plane strain small-scale yield solution

$\checkmark \quad$ Poisson's ratio

$\delta_{\mathrm{i}} \quad$ check constant

RPV reactor pressure vessel

CT compact tension

SSYC small scale yielding correction

CMOD crack mouth opening displacement
Minnebo et al. [17] investigated the fracture behavior of A533B steel in the transition region. They performed four series of $K_{\mathrm{Jc}}$ tests to obtain $\mathrm{T}$ stress and $\mathrm{T}_{0}$ values and found good agreement of $\mathrm{T}_{0}$ by Eq. (1) and by experiments. However, for the elastic-plastic condition, the connection of Q parameter to $K_{\mathrm{Jc}}$ is still lacking.

This paper aims to propose a link between the $Q$ parameter and the reference temperature $T_{0}$ of difference sized specimens.

\section{Experimental procedure and results}

\subsection{Experimental material}

The material tested in this paper is the common RPV steel A508-3, the specific chemical composition is reported in Table 1.

In order to investigate the influence of size effect on $K_{\mathrm{Jc}}$, four sizes of specimens, $1 \mathrm{CT}, 0.5 \mathrm{CT}, 0.25 \mathrm{CT}$ and mini CT $(1 / 6 \mathrm{CT})$, were studied. The sizes of these specimens are: $60 \mathrm{~mm} \times 62.5 \mathrm{~mm} \times 25 \mathrm{~mm}, 30 \mathrm{~mm} \times$ $31.2 \mathrm{~mm} \times 12.5 \mathrm{~mm}, 15 \mathrm{~mm} \times 15.6 \mathrm{~mm} \times 6.3 \mathrm{~mm}, 10 \mathrm{~mm} \times 10 \mathrm{~mm} \times$ $4 \mathrm{~mm}$. Crack depth a/W is 0.55 for all the tested specimens, as shown in Fig. 1. The 1/6CT specimens were taken from Charpy impact specimens. According to the standard ASTM E1921 [21], the test temperature range is required to be $\mathrm{T}_{0} \pm 50^{\circ} \mathrm{C}$, and the test temperatures of the specimens of different sizes are shown in Table $2 . K_{\mathrm{Jc}}$ test was carried out on a low temperature test on an ETM $304 \mathrm{C}$ microcomputer controlled electronic universal testing machine.

\subsection{Master curve method}

Wallin et al. [18-20] proposed a three-parameter Weibull formula to describe cumulative failure probability distribution of material toughness at a temperature in the ductile-brittle transition zone

$P_{f}=1-\exp \left[-\frac{B}{B_{0}}\left(\frac{K_{I C}-K_{\min }}{K_{0}-K_{\min }}\right)^{4}\right]$

where $P_{f}$ is the cumulative failure probability; $K_{J C}$ is the equivalent fracture toughness obtained by the transformation of the critical $\mathrm{J}$ integral; $\mathrm{B}_{0}$ is the reference specimen thickness, which is specified as $1 \mathrm{in}$. of the specimen thickness, i.e. $1 \mathrm{~T}$; $\mathrm{B}$ is the actual thickness of the specimen, that is $\mathrm{xT}$; the scale parameter $\mathrm{K}_{0}$ of the Weilbull distribution is the $\mathrm{K}_{\mathrm{JC}}$ value at $\mathrm{P}_{\mathrm{f}}=63.2 \%$; $\mathrm{K}_{\min }$ is the threshold toughness of the threshold, taking a fixed value of 20 , independent of the thickness and temperature of the specimen. The median $K_{\mathrm{Jc}}$ curve with a failure probability of $50 \%$ is called Master Curve, and the expression is

$K_{I C(\text { med })}=30+70 \exp \left[0.019\left(T-T_{0}\right)\right]$

$\mathrm{K}_{\mathrm{JC}}$ (med) means a specimen with thickness of $1 \mathrm{~T}$. Median $\mathrm{K}_{\mathrm{JC}}$ of different thickness is converted to that of $1 \mathrm{~T}$ by

$K_{J c(1 T)}=20+\left(K_{J C}-20\right)\left(\frac{B}{B_{0}}\right)^{1 / 4}$

The transition temperature $\mathrm{T}_{0}$ of the Master Curve is determined by setting $\mathrm{K}_{(\mathrm{med})}=100 \mathrm{MPa} \sqrt{\mathrm{m}}$ in the Master Curve expression. Alternatively, the relationship between $\mathrm{K}_{\mathrm{JC}}$ and the temperature $\mathrm{T}$ at any failure probability $P_{f}$ is

Table 1

Nominal chemical composition of A508-3steel.

\begin{tabular}{lll}
\hline Element & Experiment material & National standard \\
\hline $\mathrm{C}$ & 0.18 & $0.16-0.22$ \\
$\mathrm{Si}$ & 0.16 & $0.10-0.30$ \\
$\mathrm{Mn}$ & 1.41 & $1.20-1.60$ \\
$\mathrm{P}$ & $<0.005$ & $<0.008$ \\
$\mathrm{~S}$ & 0.0027 & $<0.008$ \\
$\mathrm{Cr}$ & 0.12 & $\leq 0.2$ \\
$\mathrm{Ni}$ & 0.75 & $0.50-0.80$ \\
$\mathrm{Mo}$ & 0.46 & $0.43-0.57$ \\
$\mathrm{Cu}$ & $<0.02$ & $\leq 0.08$ \\
$\mathrm{~V}$ & 0.005 & $\leq 0.01$ \\
$\mathrm{Al}$ & 0.02 & $\leq 0.04$ \\
$\mathrm{Co}$ & $<0.02$ & $\leq 0.03$ \\
$\mathrm{As}$ & 0.003 & $\leq 0.010$ \\
$\mathrm{Sn}$ & 0.002 & $\leq 0.010$ \\
$\mathrm{Sb}$ & 0.0015 & $\leq 0.005$ \\
$\mathrm{~B}$ & 0.0002 & $\leq 0.0005$
\end{tabular}



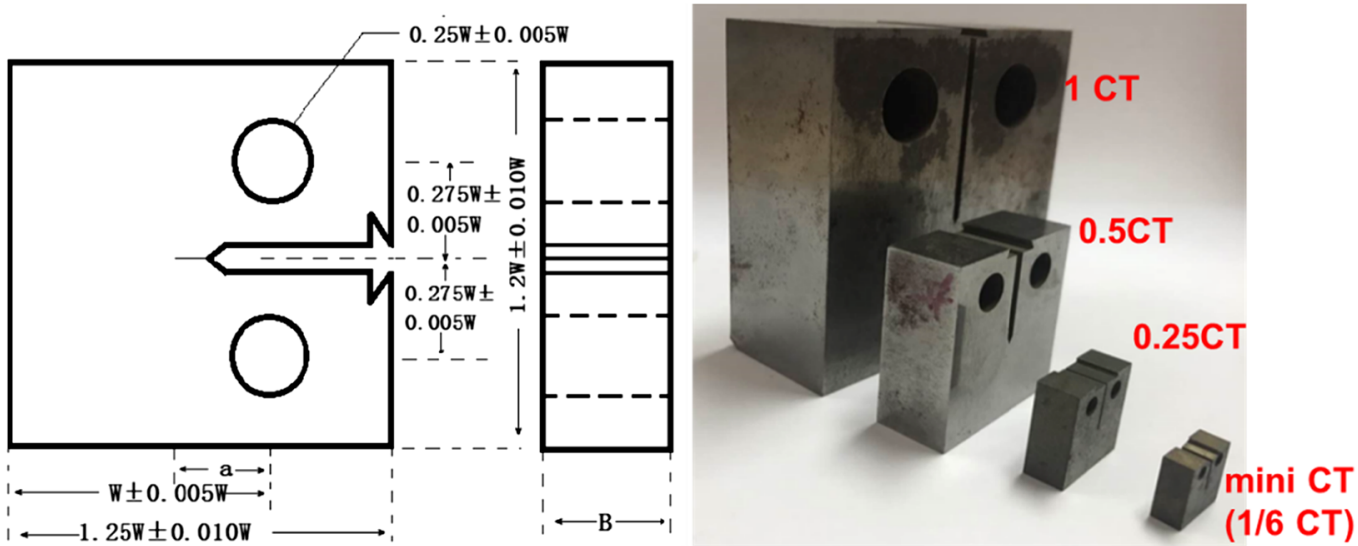

Fig. 1. Specimen geometry.

Table 2

Test temperature of specimens with different sizes.

\begin{tabular}{ll}
\hline $1 \mathrm{CT}$ & $-45^{\circ} \mathrm{C},-70{ }^{\circ} \mathrm{C}$, etc. \\
$0.5 \mathrm{CT}$ & $-25^{\circ} \mathrm{C},-45^{\circ} \mathrm{C},-50{ }^{\circ} \mathrm{C},-60{ }^{\circ} \mathrm{C},-70{ }^{\circ} \mathrm{C},-80{ }^{\circ} \mathrm{C},-100{ }^{\circ} \mathrm{C}$ \\
$0.25 \mathrm{CT}$ & $-60{ }^{\circ} \mathrm{C},-70^{\circ} \mathrm{C},-80{ }^{\circ} \mathrm{C}$ \\
$1 / 6 \mathrm{CT}$ & $-80^{\circ} \mathrm{C},-90^{\circ} \mathrm{C},-100^{\circ} \mathrm{C}$
\end{tabular}



Fig. 2. Recorded load - crack mouth opening displacement curve.

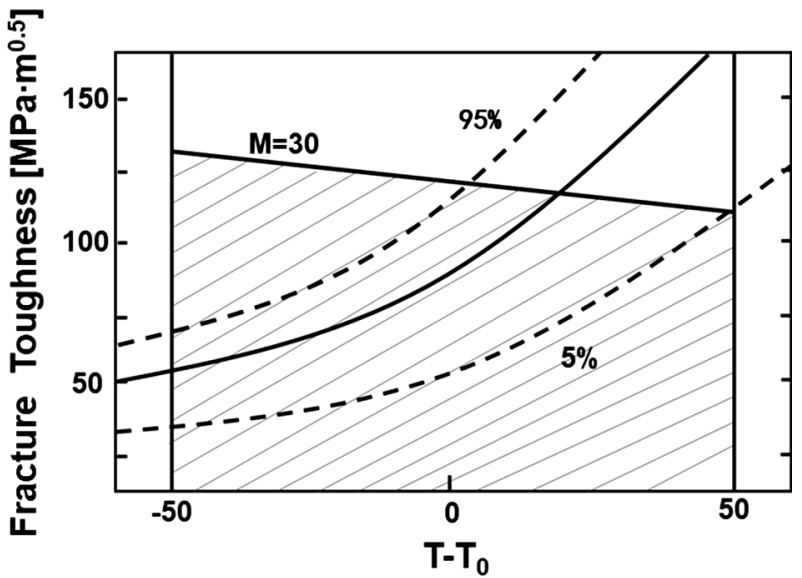

Fig. 3. Valid data window of Master Curve.

$K_{J c}\left(P_{f}\right)=20+\left[-\operatorname{Ln}\left(1-P_{f}\right)\right]^{1 / 4}\left[11+77 \exp \left(0.019\left(T-T_{0}\right)\right)\right]$

\subsubsection{Test temperature selection}

According to ASTM E1921-97 [21], methods of both single

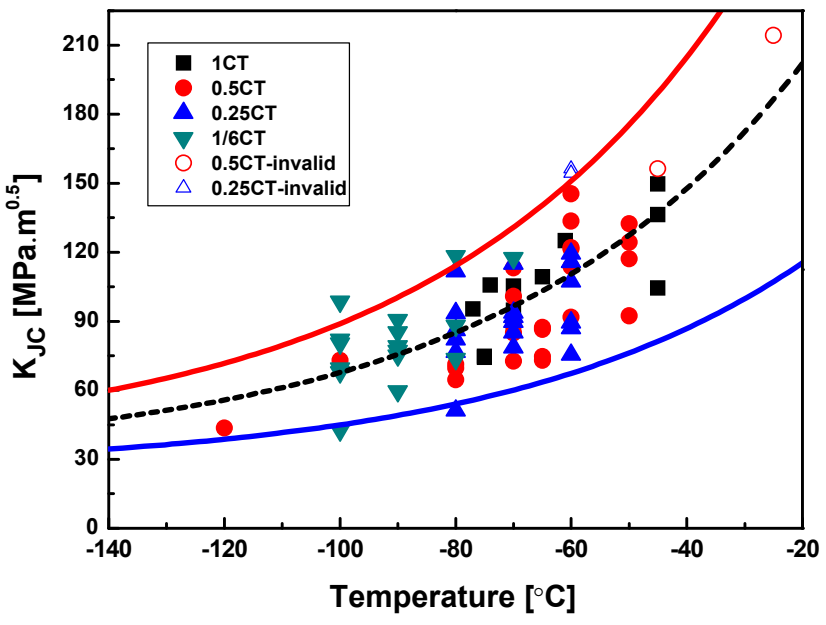

Fig. 4. Master Curve modeling of $\mathrm{K}_{\mathrm{Jc}}$ of all specimens.

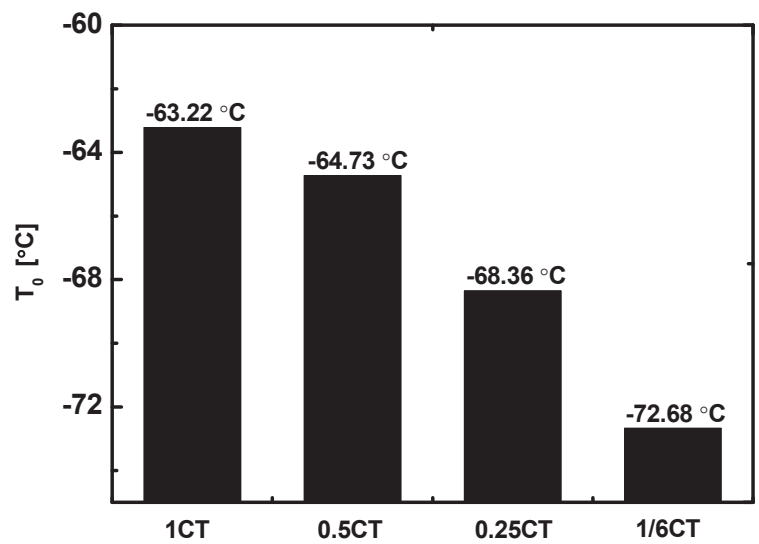

Fig. 5. Ductile-brittle transition reference temperature $T_{0}$ of specimens with different sizes.

temperature method and multi-temperature method for determining the reference temperature $T_{0}$ is provided for. The single temperature method requires at least 6-8 $K_{\mathrm{Jc}}$ data at a single temperature. The empirical formula for estimating the recommended test temperature $\mathrm{T}$ by the Charpy impact test is given as

$T=T_{41 J / 28 J}+C$

where $T_{41 \mathrm{~J} / 28 \mathrm{~J}}$ indicates the temperature corresponding to the impact absorption work of $28 \mathrm{~J}$ or $41 \mathrm{~J}$. Several specimens were selected for groping until it was found that several fracture toughness values around 


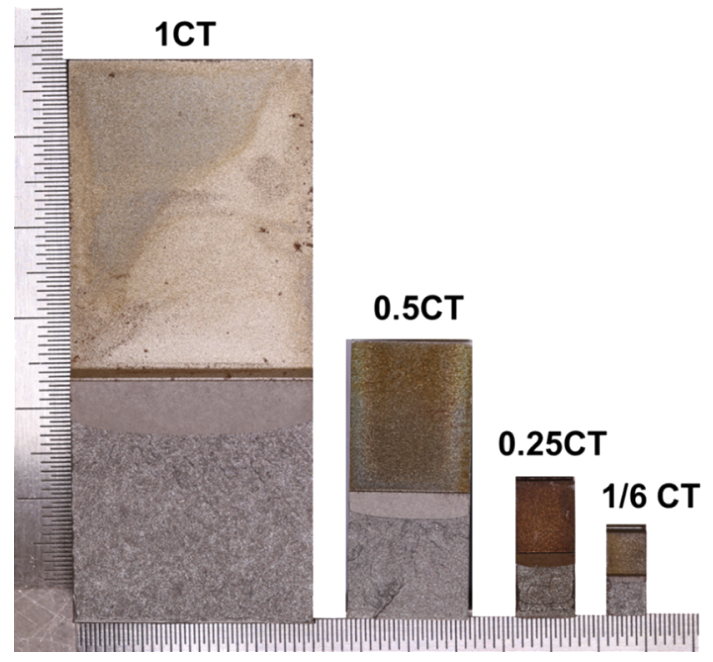

Fig. 6. Fracture surfaces of specimens with different sizes.

$100 \mathrm{MPa} \sqrt{\mathrm{m}}$ at a certain temperature.

It is considered that the critical $\mathrm{J}$ integral $\mathrm{J}_{\mathrm{c}}$ at the time of cleavage fracture initiation can be decomposed into the elastic portion $\mathrm{J}_{\mathrm{e}}$ and the plastic portion $\mathrm{J}_{\mathrm{p}}$

$J_{C}=J_{e}+J_{p}$

For compact tensile CT specimens, the formula is as follows [21]:

$J_{e}=\frac{\left(1-v^{2}\right) K_{e}^{2}}{E}$

$$
K_{e}=\frac{P_{s} f\left(a_{0} / W\right)}{\left(B B_{N} W\right)^{1 / 2}}
$$

$$
\begin{aligned}
f\left(a_{0} / W\right)= & \frac{\left(2+a_{0} / W\right)}{\left(1-a_{0} / W\right)^{3 / 2}} \times\left[0.886+4.64\left(a_{0} / W\right)-13.32\left(a_{0} / W\right)^{2}\right. \\
& \left.+14.72\left(a_{0} / W\right)^{3}-5.6\left(a_{0} / W\right)^{4}\right]
\end{aligned}
$$

$J_{p}=\frac{\eta A_{p}}{B_{N} b_{0}}$

Taking the load-crack opening displacement curve of Fig. 2 as an example, point $\mathrm{P}_{\mathrm{s}}$ is used as the parallel line of the straight line of the linear elastic section on the load-crack opening displacement curve, and the area under the curve is divided into two parts. The area $A_{p}$ represents the work of plastic deformation of the specimen. The area $A_{e}$ represents the work done by the elastic deformation of the specimen. The total area A under the curve is obtained by the integral load-crack mouth opening displacement curve.

$A_{p}=A-\frac{1}{2} C_{0} P_{S}^{2}$

For compact tensile CT specimens, the test generally records the load- displacement of the specimen. The $\eta$ factor is as follows [21]

$\eta=2+0.522 b_{0} / W$

$\mathrm{J}_{\mathrm{c}}$ is obtained from Eq. (7) and is converted to $K_{\mathrm{Jc}}$

$K_{J c}=\sqrt{\frac{J_{c} E}{1-v^{2}}}$

\subsubsection{Validity determination}

The Master Curve method requires the specimen to be cracked to maintain a highly constraint state, so as to ensure $T_{0}$ independent of the



a) $-80^{\circ} \mathrm{C}$

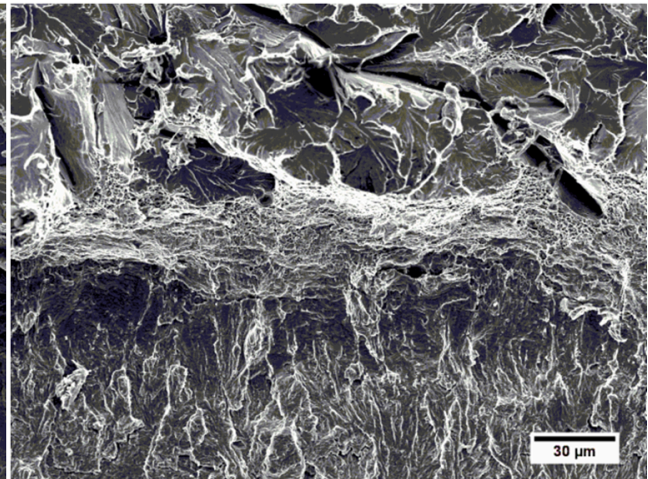

b) $-90^{\circ} \mathrm{C}$



b) $-100^{\circ} \mathrm{C}$

Fig. 7. Fracture surface of the $1 / 6 \mathrm{CT}$ specimen tested at different temperatures. 


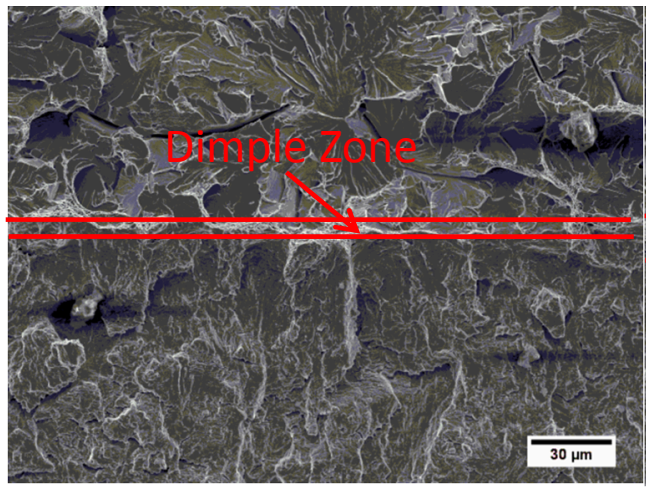

a) $1 \mathrm{CT}$ specimen

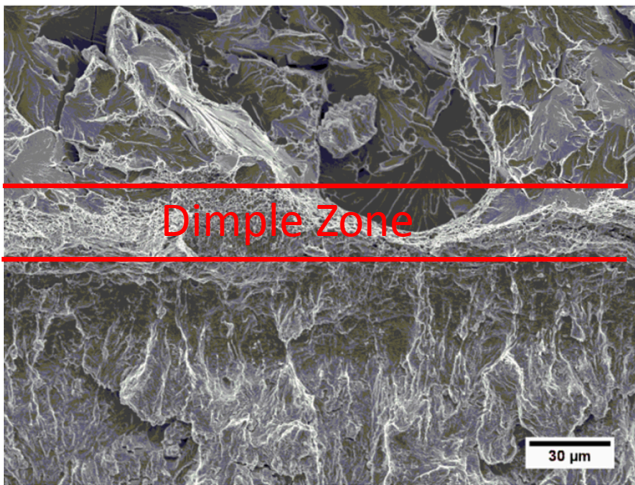

c) $0.25 \mathrm{CT}$ specimen



b ) $0.5 \mathrm{CT}$ specimen



d) $1 / 6 \mathrm{CT}$ specimen

Fig. 8. Scanning electron micrograph of fracture surfaces of specimens with different sizes tested at $-70^{\circ} \mathrm{C}$.

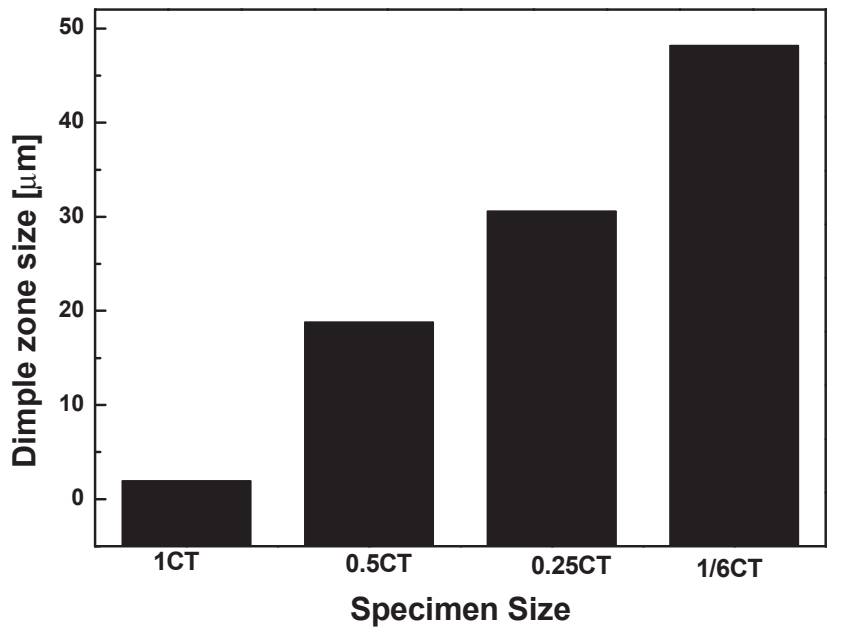

Fig. 9. Relationship between the width of the dimple region and the specimen size.

specimen size. ASTM E1921 [21] requires that $\mathrm{K}_{\mathrm{JC}}$ data not larger than K JC (limit)

$K_{I C(\text { Limit })}=\sqrt{\frac{b_{0} \sigma_{y s} E}{M_{\text {limit }}\left(1-v^{2}\right)}}$

The actual thickness of the specimen is not the standard 1T thick $\mathrm{B}=\mathrm{xT}$. The measured $\mathrm{K}_{\mathrm{Jc}}$ data should be converted into a $1 \mathrm{~T}$ thick $\mathrm{K}_{\mathrm{Jc}}$ before the calculation of $\mathrm{T}_{0}$ according to Eq. (4). The single temperature method is developed to perform fracture toughness test at the same temperature



Fig. 10. True stress-strain curve of specimen tested at $-70^{\circ} \mathrm{C}$.

$K_{0}=\sum_{i=1}^{N}\left(\frac{K_{J C(i)}-K_{\min }}{r}\right)^{1 / 4}+K_{\min }$

$\mathrm{N}$ is the total number of specimens including the effective specimen and the invalid specimen, $r$ is the number of effective specimens. The valid $\mathrm{K}_{\mathrm{JC}(\mathrm{i})}$ data is directly substituted into the calculation formula of $\mathrm{K}_{0}$. Invalid data greater than $\mathrm{K}_{\mathrm{JC} \text { (limit) }}$ is replaced by $\mathrm{K}_{\mathrm{JC} \text { (limit) }}$ and then substituted into the above formula, as shown in Fig. 3. If the $\mathrm{K}_{\mathrm{JC}}$ data is invalid due to the stable crack propagation length exceeding the standard, the invalid $\mathrm{K}_{\mathrm{JC}}$ data is the largest among all $\mathrm{N}$ specimens. The valid $\mathrm{K}_{\mathrm{JC}}$ is substituted and then substituted into the above formula. Calculate the median fracture toughness $\mathrm{K}_{\mathrm{JC}(\mathrm{med})}$ corresponding to $50 \%$ 




$1 \mathrm{CT}$

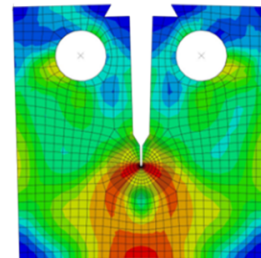

$0.5 \mathrm{CT}$

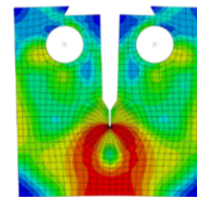

$0.25 \mathrm{CT}$

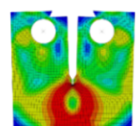

$1 / 6$ CT

Fig. 11. von Mises distributions of specimens with different sizes, note that the proportional size is not reflected in this figure.

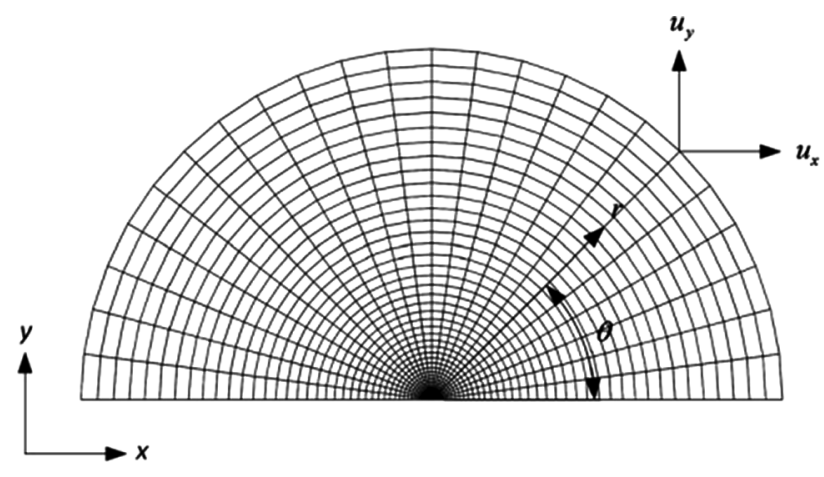

Fig. 12. Modified boundary layer model used in J-Q method.

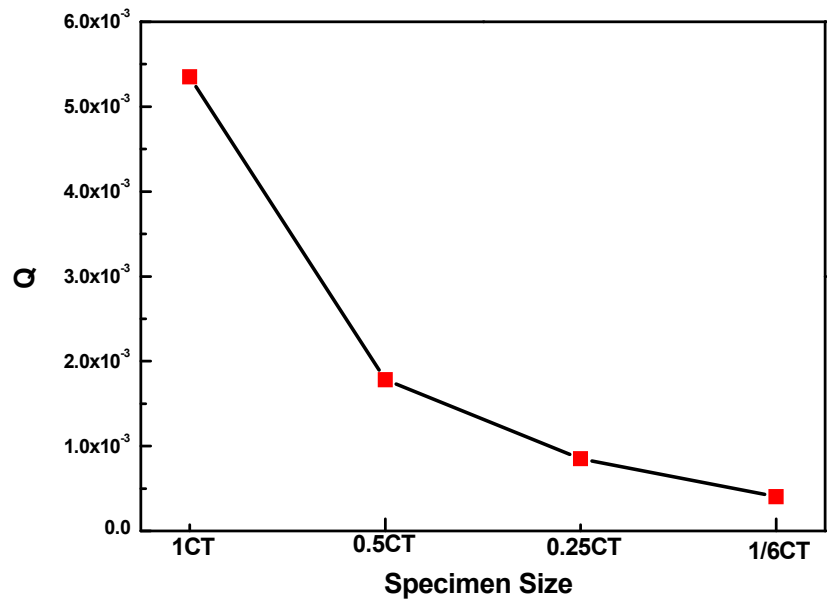

Fig. 13. Relationship between $Q$ and specimen size.

cumulative failure probability after $\mathrm{K}_{0}$ is determined,

$K_{I c(\text { med })}=\left(K_{0}-20\right)(\ln 2)^{1 / 4}+20$

Finally, the following formula is used to calculate $\mathrm{T}_{0}$

$T_{0}=T-\frac{1}{0.019} \operatorname{Ln}\left[\frac{K_{J c(\text { med })}-30}{70}\right]$

If $\mathrm{T}_{0}$ is calculated by the multi-temperature method, the calculation formula is as follows

$\sum_{i=1}^{N} \delta_{i} \exp \left(0.019\left(T_{i}-T_{0}\right)\right) /\left\{11+77 \exp \left[0.019\left(T_{i}-T_{0}\right)\right]\right\}$

$=\sum_{i=1}^{N}\left(K_{J C(i)}-20\right)^{4} \exp \left[0.019\left(T_{i}-T_{0}\right)\right] /\left\{11+77 \exp \left[0.019\left(T_{i}-T_{0}\right)\right]\right\}^{5}$

In the above formula, $\mathrm{K}_{\mathrm{JC}(\mathrm{i})}$ is the converted $\mathrm{K}_{\mathrm{Jc}}$ of $1 \mathrm{~T} . \delta_{\mathrm{i}}$ is the check constant. $\delta_{\mathrm{i}}=1$ when the data is valid, and $\delta_{\mathrm{i}}=0$ when the data is invalid.

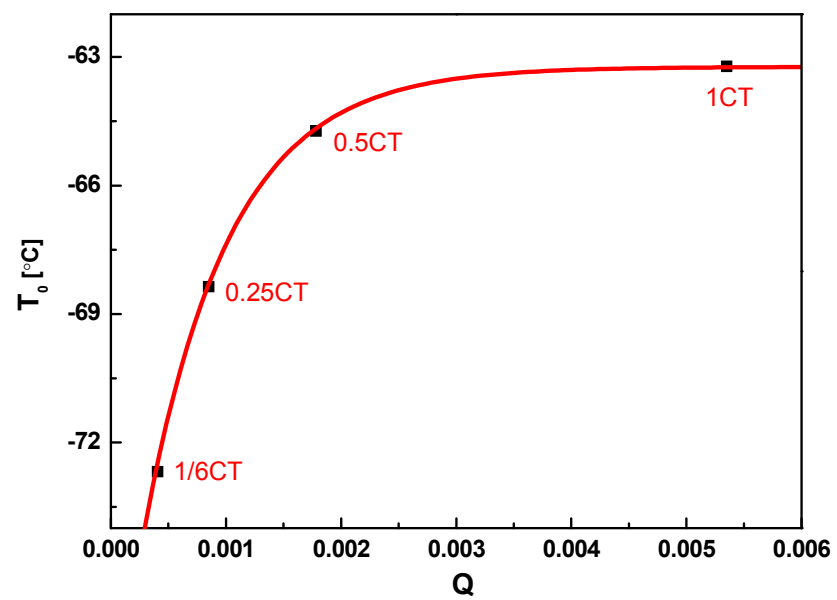

Fig. 14. The relationship between $T_{0}$ value and $Q$ value for specimens of different sizes.

\section{Results}

\subsection{Fracture toughness data}

According to ASTM E1921, the multi-temperature method requires all data in the calculation of $\mathrm{T}_{0}$. In this way, results are fitted according to Master Curve and are summarized in Fig. 4. All $\mathrm{K}_{\mathrm{JC}}$ of different sizes were converted into that of the standard 1CT specimen according to Eq. (4) and are compared in Fig. 4. The Master Curve and the upper and lower boundaries of $95 \%$ and $5 \%$ well predicted the distribution of fracture toughness (thickness converted to $1 \mathrm{~T}$ ) of the A508-3 steel CT specimen in the ductile-brittle transition zone. As the size decreases, constraint decreases and the number of invalid data increases.

$\mathrm{K}_{\mathrm{JC}}$ increases with the test temperature. It is seen that the data is valid when $1 \mathrm{CT}$ specimen is tested at $-45^{\circ} \mathrm{C}$, and the invalid data has appeared at $-45^{\circ} \mathrm{C}$ for the $0.5 \mathrm{CT}$ specimen. Invalid data appeared at $-60{ }^{\circ} \mathrm{C}$ for $0.25 \mathrm{CT}$ specimens. The test temperature was lowered and constraint was increased and the data was valid. Invalid data appeared when the smallest $1 / 6 \mathrm{CT}$ specimen was tested at $-70^{\circ} \mathrm{C}$. It is shown that as the specimen size decreases, specimen constraint decreases. At the same temperature, the smaller the size, the greater the possibility of invalid data.

$\mathrm{T}_{0}$ of different specimens is shown in Fig. 5 . It is seen that $\mathrm{T}_{0}$ of $1 / 6$ CT, $0.25 \mathrm{CT}, 0.5 \mathrm{CT}$ and $1 \mathrm{CT}$ specimen are $-72.68^{\circ} \mathrm{C},-68.36^{\circ} \mathrm{C}$, $-64.73{ }^{\circ} \mathrm{C}$ and $-63.22^{\circ} \mathrm{C}$, respectively. It is shown that $\mathrm{T}_{0}$ decreases as the size decreases, and the maximum and minimum value differs by $9.46^{\circ} \mathrm{C}$. This indicates that small specimens are not able to replace the larger specimen in the surveillance test, which affects the prediction of fracture toughness by more than $13 \%$. Therefore, further correction of the data is required to ensure that small specimens have the same reliability as standard specimens in the prediction of $\mathrm{K}_{\mathrm{Jc}}$. 


\subsection{Fracture surface analysis}

Typical fracture surfaces of the specimens with different sizes are shown in Fig. 6. The transverse line shape in the middle is a prefabricated fatigue crack. The fatigue crack part is the crack instability extension part in the pre-fabricated fatigue. It is further shown in Fig. 7 the fracture surface of the mini $(1 / 6)$ CT specimens tested at $-100^{\circ} \mathrm{C}$, $-90^{\circ} \mathrm{C}$, and $-80^{\circ} \mathrm{C}$ observed with scanning electron microscope. In the lower temperature the fracture surface demonstrates a more brittle fracture mode. For the specimen tested at $-80^{\circ} \mathrm{C}$, there is a large amount of dimple fracture area near the pre-fabricated fatigue crack. As the temperature decreases, the dimple part decreases and gradually turns into a cleavage part, which is an obvious fan-shaped cleavage plane.

Scanning electron micrographs for the fracture surfaces of the specimens with different dimensions tested at $-70{ }^{\circ} \mathrm{C}$ are shown in Fig. 8 . It is seen that the dimple zone in the 1CT specimen is the narrowest, which shows more cleavage fracture pattern. For the 1/6CT specimen, the dimple zone in the fracture surface increases significantly. The dimple zone size for all the specimens is further quantified in Fig. 9. As the specimen size decreases from 1CT to $1 / 6 \mathrm{CT}$, the dimple band gradually widens. This is consistent with the variation of $\mathrm{T}_{0}$ with the specimen size. This further confirms that the constraint of the small-size specimen is reduced and the plane strain condition is hard to be satisfied. Therefore, it is necessary to increase the stress concentration at the crack tip, so that the cleavage fracture can occur under the applied load. It is important to quantify the constraint between plane stress and plane strain condition.

\section{Finite element simulation}

Two-dimensional models corresponding to 1CT, 0.5CT, 0.25CT, and $1 / 6 \mathrm{CT}$ specimens are built with the ABAQUS software based on elasticplastic fracture mechanics. The stress-strain curve at temperature of $-70{ }^{\circ} \mathrm{C}$ is shown in Fig. 10. The elastic modulus is $195 \mathrm{GPa}$ and yield strength is $488 \mathrm{MPa}$. The true stress-strain curve is determined from engineering stress-strain curve, which is obtained from the experiment test. In the calculation, the plastic behavior of the material is assumed to follow the Ramberg-Osgood model. Displacement is applied in the rigid body according to the experiment.

The influence of constraint on the stress field at the crack tip of the specimen was studied, and the stress field distribution of the specimens of different sizes was observed. The quadratic 20-node hexahedron element (C3D20 element) is used for the finite element simulation. In order to simulate the stress singularity, the brick element is converted to a wedge element (C3D15 element). By moving the mid-point nodes to the one-quarter point and keeping the nodes on the cracked face the singularity effect will follow the law of inverse square root, i.e., for the crack front, hence avoiding the use of additional singularity elements in finite element simulation. A middle point in the symmetrical line is fixed. Element meshes, von Mises distribution of the specimens are shown in Fig. 11.

\subsection{Constraint analysis by $J-Q$ theory}

In order to properly transfer $\mathrm{K}_{\mathrm{Jc}}$ tested between different specimens, $\mathrm{J}$-Q theory is used to quantify the crack tip constraint. Under smallscale yield conditions, constraint is usually evaluated by comparing the stress field calculated by the finite element method with the stress field obtained from the reference solution of the high triaxiality.

The J-Q theory is used by many researchers to describe the near-tip stress field of two-dimensional and three-dimensional geometries. Wang [22] demonstrated that the $\mathrm{Q}$ parameter as a measure of the difference between the actual open stress and the small-scale yield solution is accurate for the range of the normalized radial distance. In the analysis presented by Silva et al. [23], plane-strain results produce relatively unchanged $\mathrm{Q}$ values when the normalized radial distance from the crack tip is varied between $1<\mathrm{r} /\left(\mathrm{J} / \sigma_{\mathrm{y}}\right)<5$. Thus, the crack tip constraint is properly quantified by $\mathrm{Q}$. $\mathrm{Q}$ is defined as

$Q=\frac{\left[\sigma_{\theta \theta}-\sigma_{(\theta \theta) r e f}\right]}{\sigma_{y}}, \theta \leq 90^{\circ}, r=2 J / \sigma_{y}$

In this study, $Q$ is calculated to quantify the crack tip constraint of the four different specimens. Fig. 12 shows the modified boundary layer model mesh and displacement boundary conditions. As shown in Fig. 13, Q decreases as the size decreases, indicating that the specimen constraint decreases as the size decreases. In this condition, plane strain may gradually changes to plane stress. This may affect $\mathrm{K}_{\mathrm{Jc}}$ prediction inaccurate. Therefore, a method to transfer $K_{\mathrm{Jc}}$ among different specimens is needed.

\section{5. $\mathrm{K}_{\mathrm{Jc}}$ transfer model}

Combining the finite element results with the experimental data, a model for predicting the ductile-brittle transition reference temperature $\mathrm{T}_{0}$ of A508-3 was established. The relationship of $\mathrm{T}_{0}$ between specimens with different geometry is developed considering Q. Suppose

$T_{0(1 T)}=T_{0(x T)}+\operatorname{Dexp}\left(B_{Q}\right)$

$\mathrm{B}_{\mathrm{Q}}$ is a function of the $\mathrm{Q}$ value, and $\mathrm{T}_{\mathrm{O}(1 \mathrm{~T})}$ is the ductile-brittle transition reference temperature $\mathrm{T}_{0}$ of the standard 1CT specimen. Substituting $\mathrm{T}_{0}$ of the different specimens obtained in the experiment and $\mathrm{Q}$ calculated in the finite element analysis, the following formula is obtained

$T_{0(1 T)}=T_{0(x T)}+16 \exp \left[\left(-\frac{Q}{7.4}\right) \exp (-4)\right]$

For the A508-3 steel used in the paper, $\mathrm{T}_{0(1 \mathrm{~T})}=-63.22^{\circ} \mathrm{C}$. Comparing the above formula with the data, it is seen that the curve fits well with the data, as shown in Fig. 14. With Eq. (22), $\mathrm{T}_{0}$ of different specimens is corrected. The model is used to convert $\mathrm{T}_{0}$ between different specimens (xT) and standard 1CT specimens. In this way, the irradiation surveillance specimen in a RPV is used properly in $\mathrm{K}_{\mathrm{Jc}}$ modeling.

\section{Conclusions}

In this paper, a series of fracture toughness test were performed for specimens with different sizes. Crack tip constraint effect was studied using J-Q theory. The following conclusions are drawn based on the present study:

1. As the specimen size increases, it is confirmed that the ductile-brittle transition temperature $T_{0}$ increases. Due to the big differences in $T_{0}$ tested by different specimens, the small specimen is not able to replace the standard specimen to predict $\mathrm{K}_{\mathrm{Jc}}$ of the RPV steel in the surveillance program.

2. At the test temperature $-70{ }^{\circ} \mathrm{C}$, scanning electron micrograph of the fracture surface shows that dimple zone in the 1CT specimen is the narrowest, which demonstrates the most obvious cleavage fracture pattern. The width of the dimple region increases significantly with the specimen size.

3. Considering constraint effect of different specimens using $Q$, a model is proposed to convert $\mathrm{T}_{0}$ between different specimens.

It is further planned to model $\mathrm{K}_{\mathrm{Jc}}$ with other local approach to fracture (multiscale, multiaxial) and a new probabilistic framework is planned for the uncertainty analysis [24-28]. Some new design of the structures inspired from composite materials made with the additive manufacturing technique may be helpful for future RPV material [29-31]. 


\section{Declaration of Competing Interest}

We hereby declare that there is no conflict of interest. This paper (or closely related research) has not been published or accepted for publication. It is not under consideration at another journal.

\section{Acknowledgements}

Financial support by Large-scale Advanced PWR Nuclear Power Plant Major Projects (2018ZX06002008), by National Natural Science Foundation of China (No. 11872364) and by CAS Pioneer Hundred Talents Program is acknowledged.

\section{References}

[1] G.R. Odette, G.E. Lucas, Embrittlement of nuclear reactor pressure vessels, J. Miner. Metals Mater. Soc. (TMS) 3 (7) (2001) 18-22.

[2] G. Qian, W.S. Lei, M. Niffenegger, V.F. Gonzalez, On the temperature independence of statistical model parameters for cleavage fracture in ferritic steels, Philos. Mag. 98 (2018) 959-1004.2.

[3] G. Qian, W.S. Lei, L. Peng, Z. Yu, M. Niffenegger, Statistical assessment of notch toughness against cleavage fracture of ferritic steels, Fatigue Fract. Eng. Mater. Struct. 41 (2018) 1120-1131.3.

[4] G. Qian, Y. Cao, M. Niffenegger, Y.J. Chao, W. Wu, Comparison of constraint analyses with global and local approaches under uniaxial and biaxial loadings, Eur. J. Mech. A-Solids 69 (2018) 135-146.4.

[5] V.S. Barbosa, R. Claudi, Fracture toughness testing using non-standard bend specimens-Part I: constraint effects and development of test procedure, Eng. Fract. Mech. 195 (2018) 279-296.

[6] T.L. Anderson, R.H. Dodds, Specimen size requirements for fracture toughness testing in the transition region, J. Test. Eval. 19 (2) (1991) 123-134.

[7] R.H. Dodds, T.L. Anderson, M.T. Kirk, A framework to correlate a/W ratio effects on elastic-plastic fracture toughness $\left(J_{c}\right)$, Int. J. Fract. 48 (1) (1991) 1-22.

[8] N.P. O'Dowd, C.F. Shih, Family of crack-tip fields characterized by a triaxiality parameter-I. Structure of fields, J. Mech. Phys. Solids 39 (8) (1991) 989-1015.

[9] N.P. O'Dowd, C.F. Shih, Family of crack-tip characterized by a triaxiality parameter - II. Fracture applications, J. Mech. Phys. Solids 40 (5) (1992) 939-963.

[10] S.G. Larsson, A.J. Carlsson, Influence of non-singular stress terms and specimen geometry on small-scale yielding at crack tips in elastic-plastic materials, J. Mech. Phys. Solids 21 (4) (1973) 263-277.

[11] G. Harlin, J.R. Willis, The influence of crack size on the ductile-brittle transition, Proc. R. Soc. London Ser. A-Math. Phys. Eng. Sci. 415 (1848) (1988) 197-226.
[12] P.S. Leevers, J.C. Radon, Inherent stress biaxiality in various fracture specimen geometries, Int. J. Fract. 19 (4) (1982) 311-325.

[13] C. Betegon, J.W. Hancock, Two-parameter characterization of elastic-plastic cracktip fields, J. Appl. Mech. 58 (1) (1991) 104-110.

[14] S. Bhowmik, P. Sahoo, S.K. Acharyya, S. Dhar, J. Chattopadhyay, Evaluation and effect of loss of constraint on master curve reference temperature of 20MnMoNi55 steel, Eng. Fract. Mech. 136 (2015) 142-157.

[15] X. Gao, R.H. Dodds, R.L. Tregoning, J.A. Joyce, Prediction of the $T_{0}$ Shift between specimens of different constraints using the T-stress based T-functions, Int. J. Fract. 104 (2000) 1-8.

[16] K. Wallin, Quantifying stress controlled constraint by the master curve transition temperature $T_{0}$, Eng. Fract. Mech. 68 (3) (2001) 303-328.

[17] P. Minnebo, C.C. Ramos, J. Mendes, L. Debarberis, Constraint-based master curve analysis of a nuclear reactor pressure vessel steel, IAEA CRP-8 Project, (2009).

[18] K. Wallin, T. Saario, K. Torronen, et al., Mechanism-based statistical evaluation of the ASTM reference fracture toughness curve, Nucl. Eng. Des. 9-14 (1984).

[19] K. Wallin, The scatter in KIC results, Eng. Fract. Mech. 19 (6) (1984) 1085-1093.

[20] K. Wallin, The size effect of in $\mathrm{K}_{\mathrm{Ic}}$ results, Eng. Fract. Mech. 22 (1) (1985) 149-163.

[21] ASTM. Standard test method for determination of reference temperature T0 for ferritic steels in the transition range, 2005.

[22] X. Wang, Two-parameter characterization of elastic-plastic crack front fields: surface cracked plates under tensile loading, Eng. Fract. Mech. 76 (2009) 958-982.

[23] L.A.L. Silva, S. Cravero, C. Ruggieri, Correlation of fracture behavior in high pressure pipelines with axial flaws using constraint designed test specimens. Part II: 3-D effects on constraint, Eng. Fract. Mech. 73 (2006) 2123-2138.

[24] G. Qian, W. Lei, Z. Tong, Z. Yu, A statistical model of cleavage fracture toughness of ferritic steel DIN 22NiMoCr37 at different temperatures, Materials 12 (2019) 982.

[25] G. Qian, W. Lei, Z. Yu, F. Berto, Statistical size scaling of breakage strength of irregularly-shaped particles, Theo. App. Fract. Mech. 102 (2019) 51-58.

[26] G. Qian, W. Lei, A statistical model of fatigue failure incorporating effects of specimen size and load amplitude on fatigue life, Philos. Mag. (2019), https://doi.org/ 10.1080/14786435.2019.1609707.

[27] D. Liao, S. Zhu, G. Qian, Multiaxial fatigue analysis of notched components using combined critical plane and critical distance approach, Inter. J. Mech. Sci. 160 (2019) 38-50.

[28] S. Xu, S. Zhu, Y. Hao, G. Qian, A new critical plane-energy model for multiaxial fatigue life prediction of turbine disc alloys, Eng. Fail. Anal. 93 (2018) 55-63.

[29] Z. Wang, W. Wu, G. Qian, J. Oliveira Correia, L. Sun, In-situ SEM investigation on fatigue behaviors of additive manufactured Al-Si10-Mg alloy at elevated temperature, Eng. Fract. Mech. 214 (2019) 149-163.

[30] W. Wu, W. Hu, G. Oian, H. Liao, X. Xu, F. Berto, Mechanical design and multifunctional applications of chiral mechanical metamaterials: a review, Mater. Des. 18 (107950) (2019) 1-13.

[31] W. Wu, X. Song, J. Liang, R. Xia, G. Qian, D. Fang, Mechanical properties of antitetrachiralauxetic stents, Comp. Struct. 185 (2018) 381-392. 